\title{
Tourist Satisfaction and Subjective Well-Being: An Index Approach
}

\author{
Melville Saayman \\ Tourism Research in Economic Environs and Society (TREES), \\ North-West University, Potchefstroom, South Africa, 2531 \\ Email: Melville.Saayman@nwu.ac.za \\ *Corresponding Author
}

\author{
Gang Li \\ School of Hospitality and Tourism Management, University of Surrey, Guildford, GU2 7XH, \\ $\mathrm{UK}$; \\ Extraordinary Professor, North West University, TREES \\ Email: G.LI@surrey.ac.uk \\ Muzaffer Uysal \\ Department of Hospitality \& Tourism Management, Isenberg School of \\ Management, University of Massachusetts, Amherst, MA, USA \\ Extraordinary Professor, North West University, TREES \\ Email: muysal@ isenberg.umass.edu \\ Haiyan Song \\ School of Hotel \& Tourism Management, The Hong Kong Polytechnic University, Kowloon, \\ Hong Kong. \\ Email: haiyan.song@polyu.edu.hk
}

\begin{abstract}
The purpose of this research is to propose an index approach to study the impact of travel experience on tourists' satisfaction and the further impact on their sense of well-being. Based on the latest development of tourist satisfaction research, that is, the tourist satisfaction indices, this innovative study further extends the two-stage framework of tourist travel experiences to account for subjective well-being and subsequently calculates a tourist well-being index. A questionnaire with 496 respondents was used, which focused on four service sectors' tourist satisfaction indices. From this, a destination overall tourist satisfaction index and a tourist well-being index were produced using the results of structural equation modelling. Some key findings include the higher the impact of the trip on tourists' sense of well-being the higher the loyalty towards the destination. Different cultures had different results concerning the trip experiences (satisfaction) and the impact of the latter on their subjective well-being. Group travellers also had a significantly more positive experience compared with solo travellers. A new innovative indices system capturing tourist satisfaction and its causes and outcomes, in particular its impact on tourists' subjective well-being, was developed. This research therefore extends work done on the impact of tourist experience and quality of life/subjective well-being.
\end{abstract}

Keyword: tourist satisfaction, subjective well-being, market segments, quality of life, index, structural equation model, South Africa

\footnotetext{
${ }^{1}$ This article should be cited as follows:

Saayman M, G. Li, M. Uysal and H. Song (2018). Tourist Satisfaction and Subjective Wellbeing: An Index Approach. International Journal of Tourism Research, 1-12. DOI: 10.1002/jtr.2190.
} 


\section{INTRODUCTION}

McDowall (2010) states that tourism is in the business of selling memorable experiences, and these experiences are made up of the different products and services that tourists encounter during their travel and stay at a destination. These tourists form their judgment of a destination by comparing their actual experiences with their expectations. If their actual experiences exceed their expectations, they will become satisfied tourists. If not, they will be dissatisfied or unhappy. From a marketing perspective, Augustyn and Ho (1998, p.73) refer to the adage that, "on average, customer loyalty is worth ten times the price of a single purchase and if customers like the service, they will tell three people; if they don't like the service, they will tell eleven people". In this context, managers need to continuously monitor tourists' satisfaction through regular and consistent customer surveys (Saayman, Marias \& Krugell, 2010). An index approach has been introduced as the latest development of tourist satisfaction research (see Li, Song, Chen \& Wu, 2012; Song, Li, Van der Veen \& Chen, 2010). These tourist satisfaction indices (TSIs) has been developed to systematically measure and monitor tourists' satisfaction with individual services and the destination as a whole. The benefits of such indices is that it provides a useful tool for destination management (Song, Van der Veen, Li \& Chen, 2012). However current indices had not until recently addressed another emerging research direction which is to determine the impact of travel and tourism experiences on tourists' subjective well-being (SWB) or quality of life (QOL). For example, Sirgy (2010) argues that life

satisfaction can be increased by engaging travel and tourism events, which can produce a positive impact on important life domains and allow that positive effect to spill over into one's overall life. A number of studies have shown empirical evidence on the significant relationship between tourists' satisfaction with a trip experience and their sense of SWB or QOL (Sirgy 2010; Sirgy, Kruger, Lee \& Grace, 2011).

It is therefore clear that a gap exists between the two areas of research on tourist satisfaction and experience. Both these aspects are important from a destination management point of view and this raises questions that requires answers such as of how can this gap be bridged from a methodological point of view? How strong is the relationship between these concepts? Therefore, this study aims to bridge the gap between the two areas of research by extending the tourist satisfaction index framework to further examine the effect of tourists' satisfaction on their sense of SWB after the trip. Using South Africa as a case destination, this study further illustrates how the developed index framework can be applied in an empirical context.

\section{LITERATURE REVIEW}

\subsection{Tourist satisfaction and an index approach}

Looking at what satisfaction implies and why it is important, Truong and Foster (2006) state that the definition of satisfaction has been discussed from different perspectives for more than 30 years. McDowall (2010) adds that satisfaction is a valuable concept in understanding the performance of a destination, and if a destination can identify the attributes that satisfy tourists, it increases its chance to attract loyal tourists. Satisfied tourists benefit a destination enormously, since they tend to be willing to pay more and stay longer at the destination; they are likely to promote the destination by word of mouth and social media; they may become loyal and repeat their visit to the destination; and more importantly, they contribute to the destination's competitiveness, and these benefits lead to a destination being more sustainable and profitable (Choi \& Chu, 2001; Dagger, 
Sweeney \& Johnson, 2007; Del Bosque \& San Martin, 2008; Rust, Zahorik \& Keiningham, 1995; Wu \& Ko, 2013).

Oliver (1997) defines tourist satisfaction as a judgment that a product or service feature, or the product or service itself, provided a pleasurable level of consumptionrelated fulfilment, which includes levels of over and under fulfilment. Pizam, Neumann and Reichel (1978, p. 317) define tourist satisfaction as a collection of tourists' attitudes about specific domains in their vacation experience. According to Chen, Lehto and Choi (2009), the quality of the experience can vary based upon the performance of the destination's service providers. In general, the experience in tourism cuts across the primary aspects such as transport, entertainment, accommodation, meals and drinks, and public services such as immigration and financial, to name a few (Saayman, 2013). Therefore the quality of the experience is in the hands of several actors or role players, and this makes tourist satisfaction very complex (Weaver, Weber \& McCleary, 2007). Even though there are several definitions concerning tourist satisfaction, one thing remains paramount, and that is that tourists carry out some form of evaluation or judgment, and based on that evaluation they are satisfied or not. How does tourist satisfaction then differ from service quality?

Service quality is defined as a tourists' assessment of the overall excellence or superiority of service (Zeithaml, 1988). Therefore service quality also identify the gaps between expectations and perceptions of actual service or performance levels (Cho, 1998). Hence although both service quality and tourist satisfaction identifies gaps, the latter relates to specific transactions (Westbrook \& Oliver, 1991). This implies that an understanding of tourist satisfaction is a requirement for developing a long-term relationship with tourists and helping marketers and managers alike in allocating their resources effectively and improving their service performance (Henning-Thurau \& Klee, 1997; Li et al., 2012).

Although many studies have been conducted concerning tourist satisfaction (see McDowall, 2010; Truong \& Foster, 2006), a consensus on which approach to follow with respect to the measurement or evaluation has not been reached. Several models are available, and three of them have attracted the most attention. They are: the expectationperception paradigm proposed by Parasuraman, Zeithaml \& Berry (1985), the performance-only model suggested by Grönroos (1984), and lastly the expectancydisconfirmation model provided by Oliver (1980). The expectation-perception model measures the gaps between tourists' expectations and perceptions of a product or service performance. While the performance-only model regards tourist satisfaction as an outcome of the actual quality of performance and its perception by tourists, Fuchs and Weiermair (2004) criticise the model, since it is not possible to interpret high levels of tourist satisfaction due to low expectations or superior quality of service. When one looks at the expectancy-disconfirmation model, it becomes clear that the tourist has established certain expectations of the performance of a service before buying the service, during which time the tourist makes compromises between the actual performance of the service and the tourist's anticipation after consumption, after which disconfirmation arises. A positive disconfirmation leads to a tourist being satisfied, which implies tourist satisfaction and willingness to repurchase. The opposite also applies in the case of a negative disconfirmation (Li et al., 2012). The expectancy-disconfirmation model has been applied most often in consumer and tourist satisfaction studies. The approach used in this paper is also based on the expectancy-disconfirmation model. 
Most assessments of tourist satisfaction within a particular destination are based on multiple attributes, including service quality, price, cleanliness, infrastructure, and so on. They do not necessarily refer to a particular service sector within the broader tourism industry, and therefore the managerial implications for service providers and destination management organisations are not always clear. Service providers within and across different sectors do not have a clear benchmark against which to evaluate their own performance. Also, most tourist satisfaction studies are based on one-off data collection, and do not take account of the dynamic nature of tourist satisfaction. A systematic and continuous assessment of tourist satisfaction across different service sectors and source markets would be more useful. For this purpose Song et al. $(2010 ; 2012)$ developed a TSI framework based on some previously developed consumer satisfaction indices (CSIs), especially the Hong Kong CSI model (Chan, Hui, Lo, Tse, Tso \& Wu, 2003), but with its own unique features. The TSI framework is a two-stage tourist satisfaction evaluation system starting with the sectoral-level assessment, which is then aggregated to the overall destination level. Figure 1 shows the conceptual model of tourist satisfaction assessment in which expectations, perceived performance and assessed value are antecedents of tourist satisfaction, and intention to complain and loyalty are consequences of tourist satisfaction.

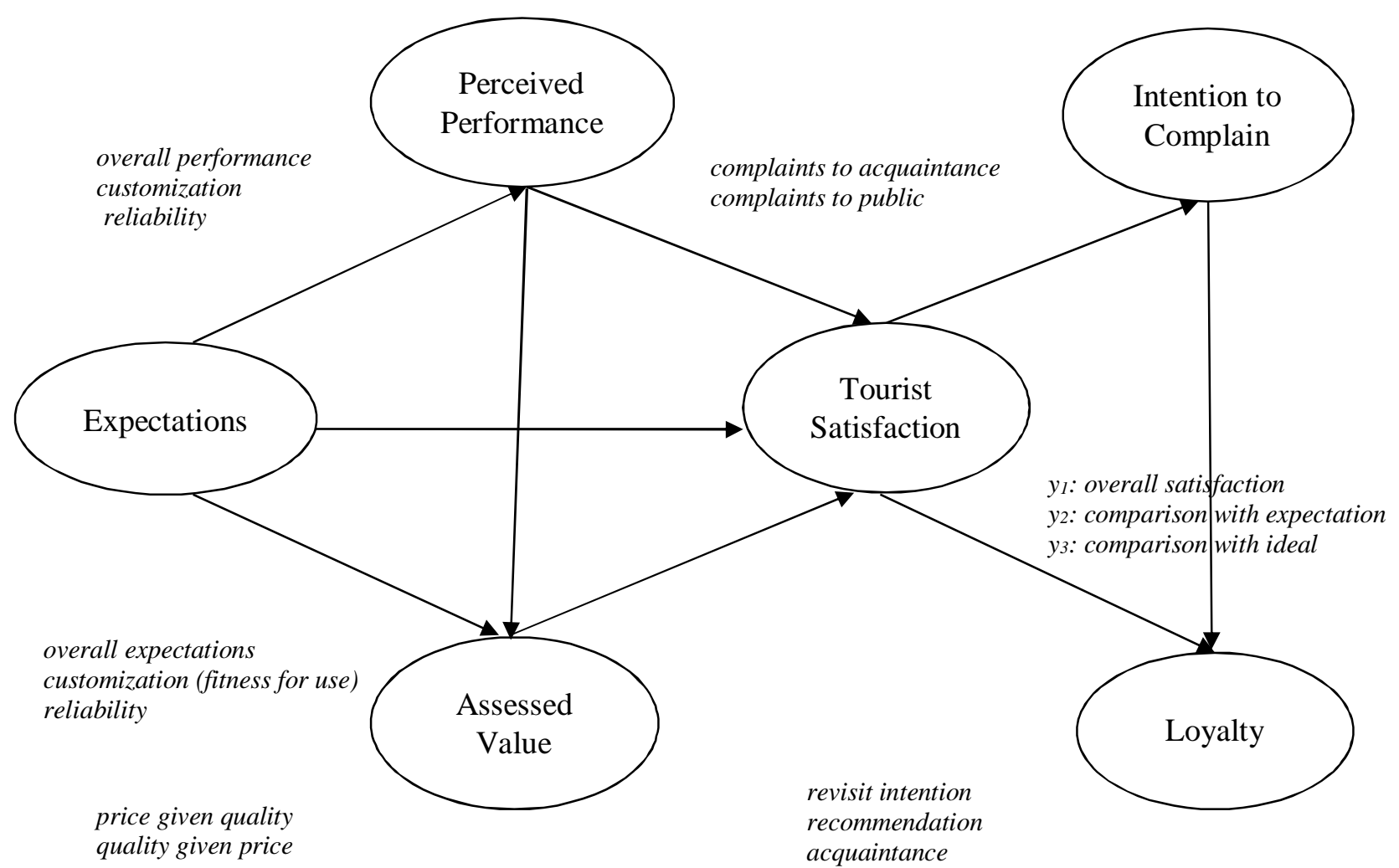

Figure 1 Sectoral TSI Model

At the first stage, each sectoral TSI is computed on the basis of this model. Paid private services such as accommodation, transportation and visitor attractions, as well as free-of-charge public services such as immigration, can be accommodated in the system. At the second stage, all sectoral TSIs are further aggregated to the destination overall evaluation using some innovative weighting schemes. Since all sectoral and destination 
TSIs are consistently expressed on a 0-100 scale, the calculated TSIs are readily comparable across different service providers within and across sectors, and even among different destinations. The TSI system also tracks the dynamic changes of tourist satisfaction over time, which allows the evaluation of the effectiveness of tourism strategies. The TSI system therefore provides a useful tool for benchmarking and continuous monitoring so as to assist effective destination management and it is easy to apply.

\subsection{Tourists' quality of life and subjective well-being}

Recently another research direction was developed in relation to tourist satisfaction, highlighting the links between tourism experience and the impact on tourists' QOL or SWB (e.g. Gilbert \& Abdullah, 2004; Neal, Sirgy \& Uysal, 1999; Neal, Uysal \& Sirgy, 2007; Sirgy et al., 2011; Tokarchuk, Maurer \& Bosnjak, 2015). Kim, Woo and Uysal (2015) note that researchers use terms such as QOL, SWB, happiness, psychological wellbeing and life satisfaction interchangeably, and it is difficult to distinguish between them, especially when referring to the subjective aspects.

Like previous literature, this study also uses both SWB and QOL with no intention of distinguishing between them. Uysal, Sirgy, Woo and Kim (2016) provide a comprehensive review of this field of study. From the 35 studies reviewed, Uysal et al. (2016) identified three sub-themes: (1) impact of travel and tourism on the QOL of individual tourists, (2) the mediating mechanism between tourism experience and QOL, and (3) moderating effects of personal, situational, and cultural characteristics on the relationship between tourism experience and QOL. Two general conclusions derive from these studies: (1) tourism experience has the potential to lead to hedonic and enduring consumption experiences, which further affect tourists' QOL or SWB; a satisfactory tourism experience tends to enhance the sense of well-being; (2) different stages in life and other background variables affect the importance of tourism in an individual's life, and therefore affect the impact of travel and tourism on overall QOL.

The research in this direction has its theoretical roots in the field of consumer wellbeing, which assumes either implicitly or explicitly that high levels of consumer wellbeing lead to higher levels of consumers' QOL, in other words, higher levels of life satisfaction, overall happiness with life, greater societal welfare, and so on (Sirgy, Grzeskowiak \& Rahtz, 2007). There are a number of conceptualisations of consumer well-being. For example, the cost of living model argues that increases in prices or inflation decrease consumers' purchasing power with respect to goods and services needed to maintain a certain level of QOL (Sirgy, Rahtz \& Samli, 2003). Therefore, inflated prices indicate the reduction of QOL.

The quality model believes that high-quality consumer goods and services are major factors in consumer well-being, and faulty and unsafe products have a negative impact on consumer well-being. The consumption complaint model, developed by the Better Business Bureau (BBB) of the United States, posits that a high level of complaints in relation to a specific company or brand represents a lower level of consumer well-being (Sirgy et al., 2007). The most commonly used theory is the bottom-up spillover theory, which implies that overall QOL is affected by the satisfaction of all life domains, e.g. health, family, leisure and recreation, finance, social life and work, which are further affected by concrete events through a "bottom-up spillover" of affect (Sirgy \& Lee, 2006). 
Thus a vocation experience affects the leisure domain of one's QOL, which further affects one's overall QOL (Neal et al., 1999, 2007).

These theoretical models shed light on the future direction of tourist satisfaction research, particularly on the extension of the TSI framework, as Figure 1 illustrates. Previous research on tourist QOL or SWB predominantly focuses on the outcomes of tourists' satisfaction with services or the overall trip experience on their SWB, and has not tracked the indirect effects of various antecedents of tourist satisfaction such as expectations, perceived performance and assessed value (i.e. quality relative to price). Neal et al. (1999, 2007) argue that QOL and satisfaction relate to all stages of service delivery experienced during a trip. Therefore, QOL and tourist satisfaction should be assessed together in a more comprehensive framework. To our knowledge, such a comprehensive framework incorporating all the above relationships between expectations, perceived performance and assessed value on the one hand, and QOL or SWB on the other, mediated by tourist satisfaction, has not been established, and these relationships have not been systematically tested in an empirical context. In addition, as the consumption complaint model suggests, tourists' intention to complain about their encountered services tends to affect their SWB negatively. Furthermore, positive impact of a travel experience on a person's SWB is likely to encourage him or her to build the loyalty with the service providers or the destination overall (e.g. Kim et al., 2015). The extended theoretical framework of TSI-SWB should incorporate these relationships too.

Following the above argument, the theoretical model of TSI in Figure 1 can be further extended, as is shown in Figure 2. Subsequently, the two-stage TSI framework can be further developed to take account of the effect on tourists' sense of SWB. The present study aims to develop such a TSI-SWB assessment framework and empirically test its applicability. This study presents the first attempt to bridge the gap between TSI and QOL/SWB research. Specifically, it not only tests the impact of tourist satisfaction on SWB, but also the relationships between the antecedents/consequences of tourist satisfaction and SWB in order to provide a more comprehensive view on how travel experience may affects one's SWB. In addition, this study introduces a tourist well-being index (TWBI) as a further extension of TSIs within the new integrated framework. 


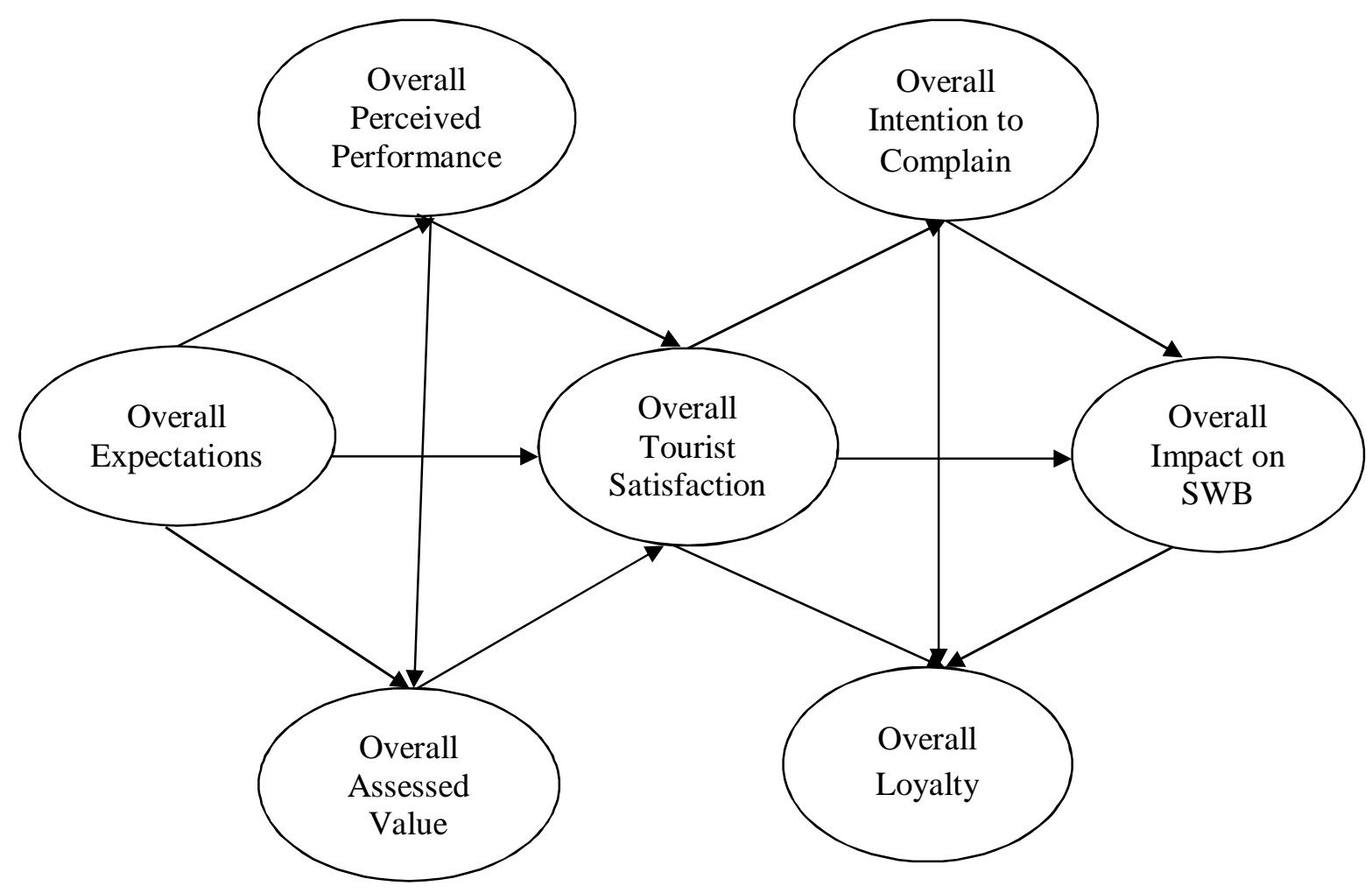

Figure 2 Destination-Level TSI-TSBWI Model

\section{METHOD OF RESEARCH}

In line with the TSI framework of Song et al. (2012), the proposed TSI-SWBI framework is tested following a two-stage process. Stage 1 is a sector-level satisfaction assessment based on the original TSI model in Figure 1. Each sector's TSI - which is the weighted average of the mean values of the satisfaction indicators - can be calculated and then converted to a scale of 0-100 for ease of comparison. Stage 2 is a destination-level assessment of tourists' overall satisfaction and further impact on their SWB based on the full model in Figure 2. In other words, the results of the individual service-sector assessment from Stage 1 are "aggregated" to form a destination overall assessment. For example, the overall tourist satisfaction in Figure 2 is measured by the latent variable scores (unstandardised) of all sectoral satisfaction constructs obtained from Stage 1.

The same measurement method applies to all constructs except SWB. Such measurement is equivalent to regarding the destination-level constructs (except SWB) as second-order latent constructs, while the sector-level constructs are first-order latent constructs, measured by the indicators shown in Figure 1. It should be noted that SWB only appears in the destination overall assessment because SWB is regarded as an accumulated outcome of the whole travel experience.

The overall TSI and TWBI are calculated on the basis of this model estimation. This proposed two-stage TSI-TWBI framework is consistent with the previous TSI framework (Song et al., 2010, 2012), but builds an even stronger and closer relationship between sector- and destination-level assessments by proposing a fuller theoretical model at the higher level, which mirrors the theoretical framework at the lower sector level. 
Moreover, from a model estimation point of view, the computing process of the proposed two-stage framework (i.e. the sectoral model in Figure 1 followed by the destination-level model in Figure 2) is equivalent to the two-stage estimation of a second-order hierarchical latent variable model (Becker, Klein \& Wetzels, 2012). Thus, the model-estimation and index-calculation results between the two stages are coherent and robust.

The research instrument of this study was a structured questionnaire comprising three sections to measure the constructs in the proposed models. Section A was about the socio-demographic details of respondents, Section B covered the measures of the six constructs (see Figure 1), namely expectations, perceived performance, assessed value, satisfaction, intention to complain, and loyalty, in relation to each of the four key service sectors that the tourists in the empirical case (i.e. South Africa) commonly experienced, namely accommodation, food and beverage, visitor attractions, and immigration services. All constructs adopted multi-item (two or three items each) measurement. The measures of all of the constructs above were adopted from Song et al. (2012). Part C included questions that measured the outcomes of the trip, i.e. the impact on SWB (QOL).

As noted by Uysal et al. (2016), there are various measures of SWB/QOL. The choice of the measure is to be "customarily contextualized to reflect the goal, target, and the research setting to adequately capture the outcome variable" (Uysal et al., 2016, p. 252). This study follows the approach of Kim et al. (2015), which implicitly assumes the trip is a cause of the outcome variables (i.e. SWB), which has been consistently approved by the existing literature. To be in line with the measurement of most other constructs, and to retain a good balance between robustness and parsimony of measurement, the impact on SWB in this study is measured by three indicators, all adopted from Kim et al. (2015, p. 471), namely "Overall, my experience with this trip was memorable having enriched my quality of life", "My satisfaction with life in general has increased with this trip", and "Overall, I feel happy after this trip". The constructs in Section B and C were measured on a 5-point scale where $1=$ completely disagree (or extremely poor) and $5=$ strongly agree (or extremely good). All constructs in the sectoral model (see Figure 1) were regarded reflectively, except intention to complain and loyalty, which were specified as formative constructs, while all constructs in the destination model (see Figure 2 ) were specified in a formative way, except SWB, which was reflective. The validity and reliability of all above constructs were assessed before the model estimation results were analysed.

As was mentioned before, South Africa was chosen as the case destination for this study as it is one of the leading destinations in Africa. In addition, growth in travel and tourism from both short-haul regional markets and long-haul international markets has increased significantly in recent years, which implies a requirement to understand the tourist experience at this developing destination (Saayman, Martin \& Roman, 2015).

The survey was conducted on 22 to 28 March 2015 in Africa's largest and busiest airport, namely OR Tambo International Airport in Johannesburg. The target respondents of the survey were foreign tourists who had completed their trip in South Africa and were on the way back to their country of residence. They could therefore give an overall evaluation of their experience. Trained fieldworkers distributed 540 self-administered questionnaires at various waiting areas for both long-haul and short-haul flights in order to capture a wide range of source markets of South African tourism. A total of 496 completed questionnaires could be used for the data analysis. As with most other tourism 
studies, data collection did not aim and could not have aimed at being entirely representative. The main purpose of this study was to illustrate the developed methodological framework and test the significance of the proposed relationships within the framework. The data collection strategy and the sample size were deemed sufficient for achieving the research objectives.

\section{DATA ANALYSIS AND RESULTS}

\subsection{Demographic profiles of the sample}

Table 1 presents the distribution of the respondents' demographic characteristics. Generally in line with the profiles of international tourists reported by South African Tourism (2015), the sample was dominated by travellers aged 25-54 and leisure travellers, with more than half being first-time visitors to South Africa. More international tourists visit South Africa with travel companies than alone.

Table 1. Demographic characteristics

\begin{tabular}{|c|c|c|c|}
\hline Variable & Average (\%) & Variable & Average (\%) \\
\hline Gender & & Education & \\
\hline Male & 62.1 & Primary/elementary school & 9.3 \\
\hline Female & 37.9 & Secondary/high school & 12.7 \\
\hline Age & & College/university & 35.5 \\
\hline Under 25 & 14.9 & Postgraduate & 21.1 \\
\hline $25-34$ & 24.3 & Other & 21.4 \\
\hline $35-44$ & 25.1 & Region of origin & \\
\hline $45-54$ & 18.5 & Africa & 50.6 \\
\hline $55-64$ & 11.0 & Non-Africa & 49.4 \\
\hline 65 and above & 6.2 & Travel party & \\
\hline Past visit experience & & Solo & 42.7 \\
\hline First-time visit & 57.8 & Group & 52.3 \\
\hline Repeated visit & 42.2 & & \\
\hline \multicolumn{4}{|l|}{ Purpose of trip } \\
\hline Leisure & 69.2 & & \\
\hline Non-leisure & 30.8 & & \\
\hline
\end{tabular}

Note: All percentages are calculated on the basis of valid responses.

\subsection{Model testing}

The computing program Smart-PLS 3.0 was employed to run SEMs. Both the inner (structural) and outer (measurement) models were estimated using an iterative procedure called the partial least squares (PLS) method. PLS has advantages over the traditional maximum-likelihood estimation method in that it does not impose distributional assumptions on the data, can accommodate both reflective and formative constructs, and has more statistical power in handling small samples (Fornell, Johnson, Anderson, Cha \& Bryant, 1996; Goodhue, Lewis \& Thompson, 2006). 
First of all, the validity of the scales was assessed. The average variance extracted (AVE) and composite reliability estimates were used to evaluate the convergent validity. The AVEs for all reflective constructs ranged between 0.69 and 0.94 , consistently above the critical value of 0.5 recommended by Fornell (1992) and Fornell and Larcker (1981). The calculated composite reliability (CR) values fell into the range of 0.87 to 0.96 (see Table 2), all higher than the threshold of 0.7. This suggested that each reflective dimension and its respective indicators were highly correlated.

In addition, a substantial degree of internal consistency among indicators of a reflective construct was evidenced by the high Cronbach's alphas, which ranged from 0.88 to 0.95 (see Table 2). Since the AVEs for all constructs were higher than the squares of all correlation coefficients, the discriminant validity was considered to be high. This finding was confirmed by a more robust measure of discriminant validity, the heterotraitmonotrait ratio (HTMT), as the HTMT values for all reflective constructs were lower than the threshold 0.90 suggested by Gold, Malhotra and Segars (2001) and Teo, Srivastava and Jiang (2008). Due to space constraints, the HTMT results have been omitted here, but are available upon request from the authors.

Table 2. Diagnostic statistics of estimated structural equation models

\begin{tabular}{|c|c|c|c|c|c|c|c|}
\hline Model & $\begin{array}{c}\text { Tourist } \\
\text { satisfaction }\end{array}$ & $\begin{array}{c}\text { Perceived } \\
\text { performance }\end{array}$ & Expectations & $\begin{array}{c}\text { Assessed } \\
\text { value }\end{array}$ & $\begin{array}{c}\text { Intention to } \\
\text { complain }\end{array}$ & Loyalty & $\overline{\mathrm{QOL}}$ \\
\hline \multicolumn{8}{|l|}{ Accommodation } \\
\hline AVE & 0.69 & 0.84 & 0.86 & 0.89 & & & \\
\hline CR & 0.87 & 0.94 & 0.95 & 0.94 & & & \\
\hline Cronbach's $\alpha$ & 0.78 & 0.90 & 0.92 & 0.88 & & & \\
\hline Redundancy $\mathrm{Q}^{2}$ & 0.26 & 0.18 & & 0.54 & 0.01 & 0.30 & \\
\hline $\mathrm{R}^{2}$ & 0.38 & 0.22 & & 0.60 & 0.01 & 0.38 & \\
\hline \multicolumn{8}{|l|}{ Food and beverage } \\
\hline AVE & 0.73 & 0.83 & 0.85 & 0.86 & & & \\
\hline CR & 0.89 & 0.94 & 0.95 & 0.93 & & & \\
\hline Cronbach's $\alpha$ & 0.81 & 0.90 & 0.91 & 0.84 & & & \\
\hline Redundancy $\mathrm{Q}^{2}$ & 0.30 & 0.11 & & 0.51 & 0.01 & 0.46 & \\
\hline $\mathrm{R}^{2}$ & 0.55 & 0.16 & & 0.78 & 0.02 & 0.67 & \\
\hline \multicolumn{8}{|l|}{ Attractions } \\
\hline AVE & 0.70 & 0.84 & 0.87 & 0.89 & & & \\
\hline CR & 0.88 & 0.94 & 0.95 & 0.94 & & & \\
\hline Cronbach's $\alpha$ & 0.79 & 0.91 & 0.93 & 0.88 & & & \\
\hline Redundancy $\mathrm{Q}^{2}$ & 0.22 & 0.18 & & 0.54 & 0.01 & 0.39 & \\
\hline $\mathrm{R}^{2}$ & 0.33 & 0.21 & & 0.61 & 0.01 & 0.51 & \\
\hline \multicolumn{8}{|l|}{ Immigration } \\
\hline AVE & 0.76 & 0.88 & 0.90 & 0.91 & & & \\
\hline CR & 0.90 & 0.96 & 0.96 & 0.95 & & & \\
\hline $\begin{array}{l}\text { Cronbach's } \alpha \\
\text { Redundancy } Q^{2} \\
\mathrm{R}^{2}\end{array}$ & 0.84 & 0.93 & 0.94 & 0.90 & & & \\
\hline \multicolumn{8}{|l|}{ Destination overall } \\
\hline AVE & & & & & & & 0.86 \\
\hline $\mathrm{CR}$ & & & & & & & 0.95 \\
\hline Cronbach's $\alpha$ & & & & & & & 0.92 \\
\hline Redundancy $\mathrm{Q}^{2}$ & 0.36 & 0.14 & & 0.47 & 0.01 & 0.39 & 0.38 \\
\hline $\mathrm{R}^{2}$ & 0.54 & 0.22 & & 0.78 & 0.04 & 0.59 & 0.45 \\
\hline
\end{tabular}

Note: 1. AVE is not applicable to formative constructs such as Intention to complain and Loyalty in sectoral models and any constructs except $Q O L$ in the destination level. 2. The R-square and the redundancy $\mathrm{Q}^{2}$ are not applicable to Expectations, as it is an exogenous variable. 
With respect to the overall model fit, the standardised root mean square residual (SRMR) can be used as a criterion. SRMR is based on transforming both the sample covariance matrix and the predicted covariance matrix into correlation matrices, and examines the average magnitude of the discrepancies between observed and expected correlations (Hair, Hult, Ringle \& Sarstedt, 2016). Across all the estimated models, SRMR values varied between 0.057 and 0.081 , all lower than the threshold of 0.10 (Hair et al., 2016), which suggested good model fits in all cases.

\subsection{Structural relationships}

Model validity was assessed by determining the significance of the estimated path coefficients using the bootstrapping option, which is a nonparametric resampling technique for estimating standard errors and approximate confidence. To ensure the robustness of standard error estimates to assess the significance of the path coefficients, 500 resamples were generated randomly from the observed dataset for each estimated model. The results of sectoral model estimation are shown in Table 2, and the results of the destination-level model estimation are presented in Figure 3.

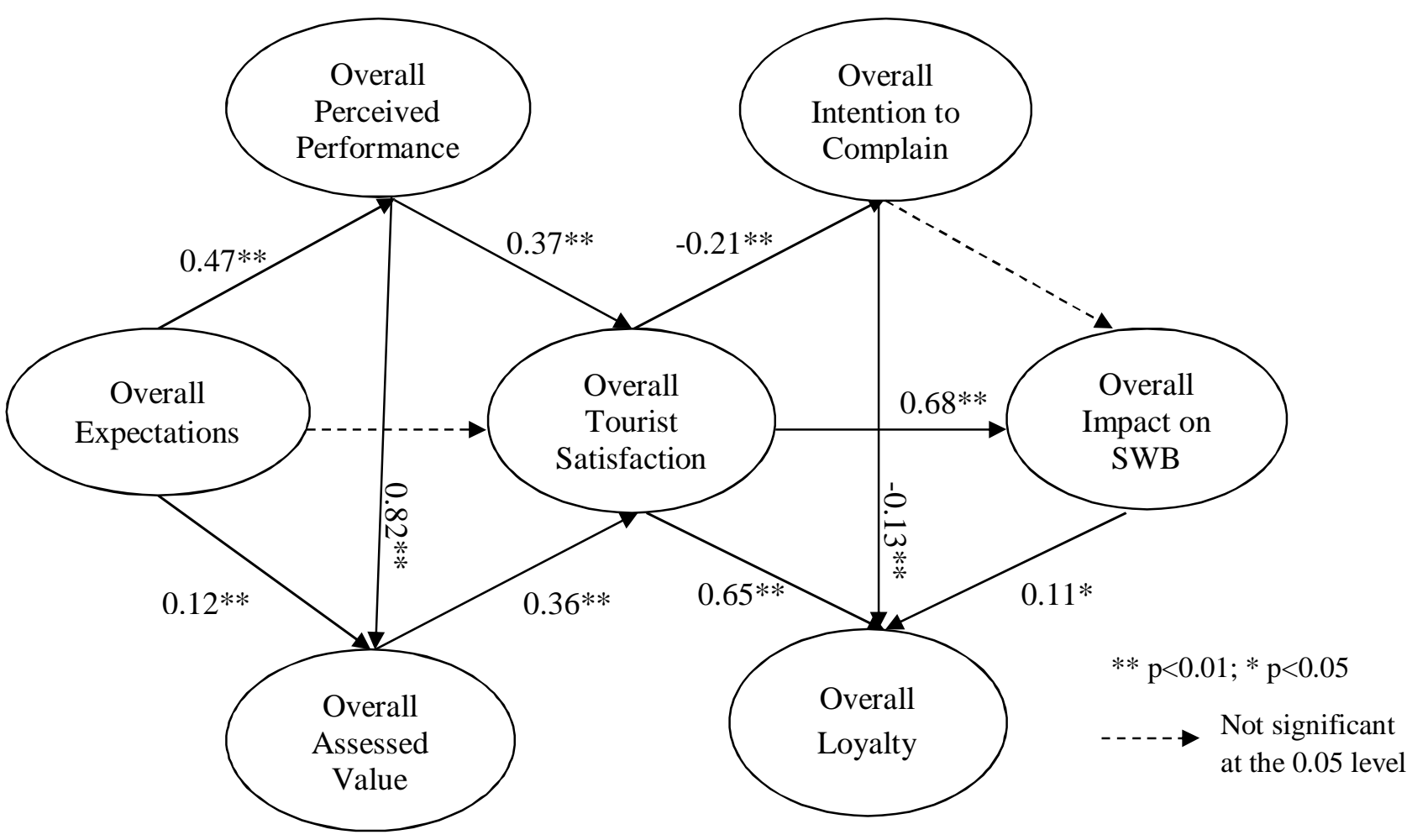

Figure 3 Estimated Destination-Level Structural Equation Model

Overall, 40 of the 48 proposed path relationships across five estimated models were statistically significant. The non-significant direct relationships between expectations and tourist satisfaction in most cases were in line with the findings of Song et al. $(2010,2012)$, indicating that the effect of expectations on tourist satisfaction was more likely to be indirect, mediated by the perceived performance and assessed value of encountered services. Taking both direct and indirect effects in account, the total effects of three antecedents (i.e. expectations, perceived performance and assessed value) on tourist satisfaction were all significant as far as both sector-level and destination-level assessments were concerned (see Tables 3 and 4). 
Table 3. Path relationships and total effects in sectoral models

\begin{tabular}{|c|c|c|c|c|}
\hline $\begin{array}{l}\text { Direct and } \\
\text { total effects }\end{array}$ & Accommodation & $\begin{array}{l}\text { Food and } \\
\text { beverage }\end{array}$ & $\begin{array}{c}\text { Visitor } \\
\text { attractions }\end{array}$ & Immigration \\
\hline \multicolumn{5}{|l|}{ Direct effect (path coefficient) } \\
\hline $\begin{array}{l}\text { Expectations } \rightarrow \text { Perceived } \\
\text { performance }\end{array}$ & $0.47 * *$ & $0.37 * *$ & $0.46^{* *}$ & $0.46^{* *}$ \\
\hline Expectations $\rightarrow$ Assessed value & $0.08^{*}$ & $0.11 * *$ & $0.10^{*}$ & $0.12 * *$ \\
\hline Expectations $\rightarrow$ Tourist satisfaction & 0.08 & 0.02 & $0.13 * *$ & 0.02 \\
\hline $\begin{array}{l}\text { Perceived performance } \rightarrow \text { Assessed } \\
\text { value }\end{array}$ & $0.74 * *$ & $0.73^{* *}$ & $0.73^{* *}$ & $0.76^{* *}$ \\
\hline $\begin{array}{l}\text { Perceived performance } \rightarrow \text { Tourist } \\
\text { satisfaction }\end{array}$ & $0.32 * *$ & $0.45 * *$ & $0.37 * *$ & $0.34 * *$ \\
\hline $\begin{array}{l}\text { Assessed value } \rightarrow \text { Tourist } \\
\text { satisfaction }\end{array}$ & $0.30 * *$ & $0.23 * *$ & $0.16^{* *}$ & $0.43 * *$ \\
\hline $\begin{array}{l}\text { Tourist satisfaction } \rightarrow \text { Intention to } \\
\text { complain }\end{array}$ & $-0.11^{*}$ & $-0.13^{*}$ & -0.09 & $-0.21 * *$ \\
\hline Tourist satisfaction $\rightarrow$ Loyalty & $0.60 * *$ & $0.73^{* *}$ & $0.69^{* *}$ & $0.72 * *$ \\
\hline Intention to complain $\rightarrow$ Loyalty & -0.08 & -0.04 & $-0.11^{* *}$ & $-0.13^{* *}$ \\
\hline \multicolumn{5}{|l|}{ Total effect on tourist satisfaction } \\
\hline Expectations & $0.36 * *$ & $0.27 * *$ & $0.37 * *$ & $0.37 * *$ \\
\hline Perceived performance & $0.54 * *$ & $0.61 * *$ & $0.48 * *$ & $0.67 * *$ \\
\hline Assessed value & $0.30 * *$ & $0.23 * *$ & $0.16^{* * *}$ & $0.43 * *$ \\
\hline
\end{tabular}

Note: The numbers in parentheses are $t$-statistics. ${ }^{* *}$ denotes $\mathrm{p}<0.01$, and $*$ denotes $\mathrm{p}<0.05$.

Table 4. Path relationships and total effects in the destination-level model

\begin{tabular}{lrr}
\hline Total effect & Value & $t$-statistic \\
\hline Overall expectations $\rightarrow$ Overall perceived performance & $0.47^{* *}$ & 11.37 \\
Overall expectations $\rightarrow$ Overall assessed value & $0.51^{* *}$ & 12.30 \\
Overall expectations $\rightarrow$ Overall intention to complain & $-0.9^{* *}$ & 3.35 \\
Overall perceived performance $\rightarrow$ Overall assessed value & $0.82^{* *}$ & 35.1 \\
Overall perceived performance $\rightarrow$ Overall intention to complain & $-0.14^{* *}$ & 3.30 \\
Overall assessed value $\rightarrow$ Overall intention to complain & $-0.07^{*}$ & 2.56 \\
Overall tourist satisfaction $\rightarrow$ Overall intention to complain & $-0.21^{* *}$ & 3.59 \\
Overall expectations $\rightarrow$ Overall tourist satisfaction & $0.41^{* *}$ & 9.82 \\
Overall perceived performance $\rightarrow$ Overall tourist satisfaction & $0.66^{* *}$ & 19.81 \\
Overall assessed value $\rightarrow$ Overall tourist satisfaction & $0.36^{* *}$ & 5.27 \\
Overall expectations $\rightarrow$ SWB & $0.28^{* *}$ & 8.07 \\
Overall perceived performance $\rightarrow$ SWB & $0.45^{* *}$ & 13.63 \\
Overall assessed value $\rightarrow$ SWB & $0.24^{* *}$ & 5.29 \\
Overall tourist satisfaction $\rightarrow$ SWB & $0.67^{* *}$ & 20.12 \\
Overall intention to complain $\rightarrow$ SWB & 0.03 & 0.65 \\
Overall expectations $\rightarrow$ Overall loyalty & $0.31^{* *}$ & 9.01 \\
Overall perceived performance $\rightarrow$ Overall loyalty & $0.502^{* *}$ & 15.34 \\
Overall assessed value $\rightarrow$ Overall loyalty & $0.27^{* *}$ & 5.077 \\
Overall tourist satisfaction $\rightarrow$ Overall loyalty & $0.755^{* *}$ & 35.138 \\
Overall intention to complain $\rightarrow$ Overall loyalty & $-0.128^{* *}$ & 3.219 \\
SWB $\rightarrow$ Overall loyalty & $0.114^{*}$ & 2.464 \\
\hline S
\end{tabular}

Note: $* *$ denotes $\mathrm{p}<0.01$, and $*$ denotes $\mathrm{p}<0.05$.

Among the three antecedents, perceived performance had the highest effect on tourist satisfaction, highlighting the importance of delivering high-standard, reliable and customised services. Focusing on 
the destination-level overall assessment, 10 out of 12 proposed path relationships were statistically significant. The exceptions were overall expectations to overall tourist satisfaction, and overall intention to complain to overall impact on SWB. In particular, a high path coefficient (0.68) was found between overall tourist satisfaction and the impact on SWB. This finding was in line with most of the previous literature (Uysal et al., 2016). In addition, the results showed that the higher the impact of the trip on a tourist's sense of well-being, the higher the loyalty the tourist is likely to develop towards the destination. This confirmed the findings of previous studies such as Kim et al. (2015). Moreover, this study found significant indirect effects of overall expectations, overall perceived performance and overall assessed value on the impact of the trip on a tourist's SWB, with overall perceived performance playing the most important role. Hence this study revealed various channels and an overall mechanism of how service delivery at a destination affects tourists' experience, further enhancing their subjective well-being.

The findings have important implications for destination management and marketing, since, in the current increasingly competitive market environment, effective strategies of destination management and marketing should be more sophisticated. The emphasis needs to go beyond just tourist satisfaction and take account of the more profound benefit of the visit experience for tourists' subjective well-being, as it further contributes to repeat visitation (loyalty) and positive word of mouth. Bearing in mind the significant effects of perceived performance and assessed value, not only on tourist satisfaction but also on tourists' sense of well-being, destination managers and service providers need to pay more attention to the quality, price and value of their products/services. This finding also highlighted the importance of continuous research in order to keep abreast of tourists' changing needs.

\subsection{Index calculation and comparisons}

On the basis of the above model estimation results, sector-level TSIs and the destination overall TSI, as well as the overall TWBI, were calculated. With regard to sectoral TSIs, the calculation was based on the estimated outer loadings $\left(\omega_{1}, \omega_{2}\right.$ and $\left.\omega_{3}\right)$ of the three tourist-satisfaction measurement indicators $\left(\mathrm{y}_{1}, \mathrm{y}_{2}\right.$ and $\left.\mathrm{y}_{3}\right)$. The outer loadings were used as the weights to calculate the unstandardised latent scores for each respondent and the sample mean, which were then converted from a 1-5 scale to a 0-100 scale for ease of comparison. Specifically, they were calculated as:

Sectoral TSI $=\left(\frac{\omega_{1} \bar{y}_{1}+\omega_{2} \bar{y}_{2}+\omega_{3} \bar{y}_{3}}{\omega_{1}+\omega_{2}+\omega_{3}}-1\right) \times 25$

where $\bar{y}_{1}, \bar{y}_{2}$ and $\bar{y}_{3}$ were the mean scores of the three tourist-satisfaction measurement indicators.

Following the same principle, the overall destination TSI and TWBI were calculated on the basis of the estimation results of the destination model.

Destination TSI $=\left(\frac{\varphi_{1} \bar{S}_{1}+\varphi_{2} \bar{S}_{2}+\varphi_{3} \bar{S}_{3}+\varphi_{3} \bar{S}_{4}}{\varphi_{1}+\varphi_{2}+\varphi_{3}+\varphi_{4}}-1\right) \times 25$

where $\bar{S}_{1}, \bar{S}_{2}, \bar{S}_{3}$ and $\bar{S}_{4}$ were the mean latent scores of tourist satisfaction with four service sectors, and $\varphi_{1}, \varphi_{2}, \varphi_{3}$ and $\varphi_{4}$ were the corresponding outer weights.

$\mathrm{TWBI}=\left(\frac{\rho_{1} \bar{z}_{1}+\rho_{2} \bar{z}_{2}+\rho_{3} \bar{z}_{3}}{\rho_{1}+\rho_{2}+\rho_{3}}-1\right) \times 25$

where $\bar{z}_{1}, \bar{z}_{2}$ and $\bar{z}_{3}$ were the mean scores of the three SWB measurement indicators, and $\rho_{1}, \rho_{2}$ and $\rho_{3}$ were the estimated outer loadings of the respective indicators.

Figure 4 shows the calculated indices. At sector level, the attractions sector received the highest TSI score of 74.4, while immigration services received the lowest TSI score of 69.2. Overall, the destination received a TSI score of 71.2. With regard to the further impact on tourists' SWB, tourists 
in South Africa had an overall TWBI score of 77.3, higher than any TSI scores at either the sector or destination level, suggesting a strong sense of well-being as a result of a travel experience.

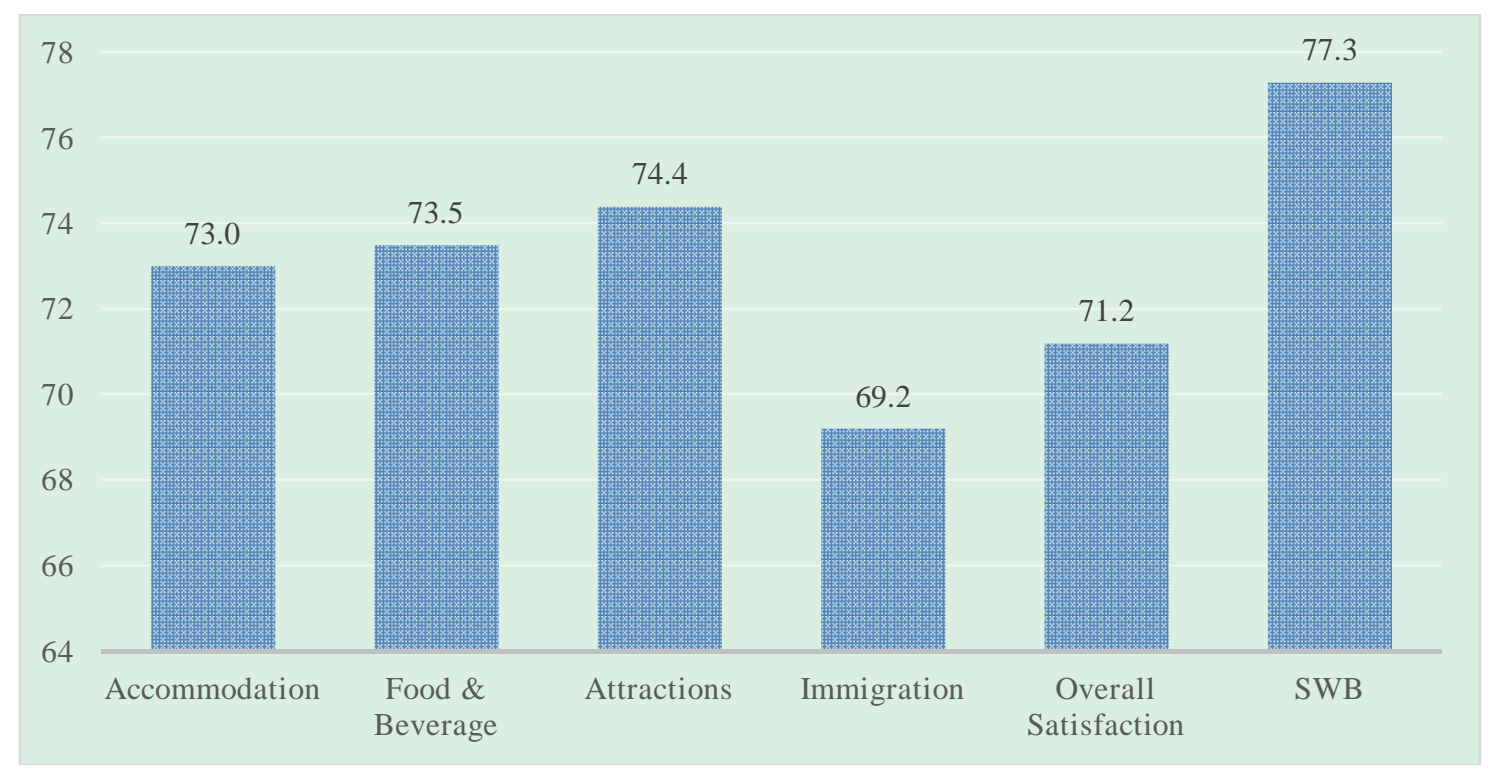

Figure 4 Calcuated TSIs and TWBIs

With the heterogeneity of tourists' experiences taken into account, the moderating effects of various demographic variables and travel patterns on the proposed path relationships can be assessed through the multi-group analysis. For example, it is useful to know whether the strength of path relationships varies between male and female tourists, between leisure and non-leisure travellers, between first-time and repeat visitors, between solo and group travellers, between regional and international visitors, and so on. The results were statistically non-significant, which indicated the universal stability of the proposed path relationships.

As a next step, we tested whether the calculated TSIs and TWBI varied according to demographic characteristics and travel patterns. Table 5 presents the statistically significant results. Firstly, crossregional non-African tourists tended to have significantly higher TSI and TWBI scores than regional African tourists. The widest gap lay in TWBI scores (80.6 versus 73.9). The finding can be explained by the relatively high cultural distance, less familiarity and low expectations of non-African tourists towards South Africa, and therefore they tended to gain higher satisfaction and well-being benefit from such an exotic travel experience. The higher TSIs of long-haul tourist markets compared to their shorthaul counterparts were in line with the findings of TSIs in Hong Kong (The Hong Kong Polytechnic University, 2015).

Another reason is explained by the findings of Saayman and Saayman (2012), who found that African tourists travel to South Africa primarily for shopping purposes. The higher perception of SWB by long-haul markets was broadly in line with the findings of Neal et al. (2007) that QOL was more evident with tourists who stay for longer, compared to those who have a shorter stay. Understandably, long-haul tourists tend to stay in a destination longer than their short-haul counterparts do. Therefore, it is beneficial not only from an economic point of view to increase the length of stay, but also from a tourists' QOL perspective.

Secondly, group travellers see a significantly more positive impact of the trip to South Africa on their SWB compared to solo travellers. One of the reasons for this is the role that group interaction and communication play in travel. This implies that the destination marketing authority should encourage group travel instead of focusing solely on fully independent travel (FIT). 
Thirdly, compared to non-leisure travellers, leisure travellers receive significantly higher TSI scores on accommodation, food and beverage, attractions and the TWBI score. The higher TWBI scores of leisure travellers and group travellers were not beyond expectations, because such travel met the needs of their leisure and social domains of life, and therefore contributed to the enhanced overall quality of life (Sirgy et al., 2007; Sirgy et al., 2011). Lastly, female tourists received higher TSI scores on food and beverage and attractions than male tourists. This finding was supported by previous literature, which states that female consumers tend to provide more moderate or less harsh evaluations (Hofstede, Hofstede \& Minkov, 1991).

Table 5. T-tests of the calculated TSIs and TWBI

\begin{tabular}{|c|c|c|c|c|c|c|c|}
\hline & & 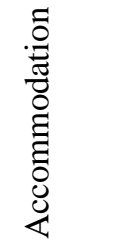 & 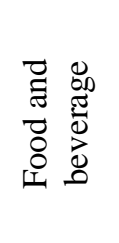 & 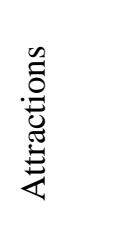 & 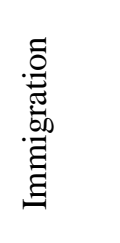 & 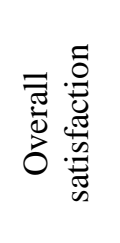 & $\sum_{\infty}^{\infty}$ \\
\hline \multirow[t]{2}{*}{ Region } & Africa & $70.3 * *$ & $70.5^{* *}$ & $71.9 * *$ & $66.9 * *$ & $69.0 * *$ & $73.9 * *$ \\
\hline & Non-Africa & $75.6 * *$ & $76.4 * *$ & $76.7 * *$ & $71.5 * *$ & $73.7 * *$ & $80.6 * *$ \\
\hline \multirow[t]{2}{*}{ Party } & Solo & 72.0 & 72.8 & 73.7 & 67.5 & 70.2 & $75.2 *$ \\
\hline & Group & 73.8 & 74.0 & 75.0 & 70.5 & 72.4 & $78.8^{*}$ \\
\hline \multirow[t]{2}{*}{ Purpose } & Leisure & $75.6^{*}$ & $76.7^{* *}$ & $76.8 * *$ & 70.3 & 73.0 & $82.0 * *$ \\
\hline & Non-leisure & $71.9 *$ & $72.1 * *$ & $73.3^{*}$ & 68.8 & 70.7 & $75.2 * *$ \\
\hline \multirow[t]{2}{*}{ Gender } & Male & 72.3 & $72.3 *$ & $73.2 *$ & 68.4 & 70.6 & 77.3 \\
\hline & Female & 74.3 & $75.5^{*}$ & $76.5^{*}$ & 70.2 & 72.7 & 77.3 \\
\hline
\end{tabular}

Note: $* *$ denotes $\mathrm{p}<0.01$, and $*$ denotes $\mathrm{p}<0.05$.

Table 6. Comparisons of calculated satisfaction and SWB indices across regions

\begin{tabular}{lccccc}
\hline & Asia & Europe & $\begin{array}{c}\text { North } \\
\text { America }\end{array}$ & $\begin{array}{c}\text { Central and South } \\
\text { America }\end{array}$ & Africa \\
\hline Accommodation & 67.2 & 77.2 & 77.5 & 79.3 & 70.3 \\
Food and beverage & 68.8 & 78.4 & 76.7 & 80.2 & 70.5 \\
Attractions & 69.9 & 77.2 & 78.7 & 81.6 & 72.0 \\
Immigration & 70.6 & 69.7 & 72.2 & 77.8 & 67.0 \\
Overall satisfaction & 69.5 & 73.2 & 74.3 & 78.8 & 68.8 \\
SWB & 73.6 & 80.3 & 86.6 & 81.0 & 73.9 \\
\hline
\end{tabular}

Note: due to a very small number of responses from the region, the Middle East is excluded from this table.

Furthermore, TSIs and TWBI of different source markets were calculated for further comparisons. Figures 5 and 6 show the results of key source regions and countries. It should be noted that, due to a small number of respondents from the Middle East, this region was excluded from Figure 5. As Figure 5 suggests, tourists from Central and South America showed the highest satisfaction with services in all sectors and overall, compared to other market regions. North America was the second most satisfied market overall, followed by Europe and Asia.

With regard to relative satisfaction among the four service sectors, five regions of source markets showed quite different patterns. North American, Central/South American and African tourists were most satisfied with attractions in South Africa, European tourists were most satisfied with food and beverage, while Asian tourists were most satisfied with immigration services. With respect to TWBIs, 
tourists from North America perceived the highest impact on their well-being from the trip to South Africa, followed by Central and South America and Europe. African and Asian tourists sensed a relatively low impact on their well-being. Different perceptions and evaluations by different markets indicated the cultural difference and their different expectations and needs from a travel experience (Ap, 2000; Crotts \& Erdmann, 2000). From a management and marketing perspective it would make sense to determine how service levels can be improved in the context of these markets.

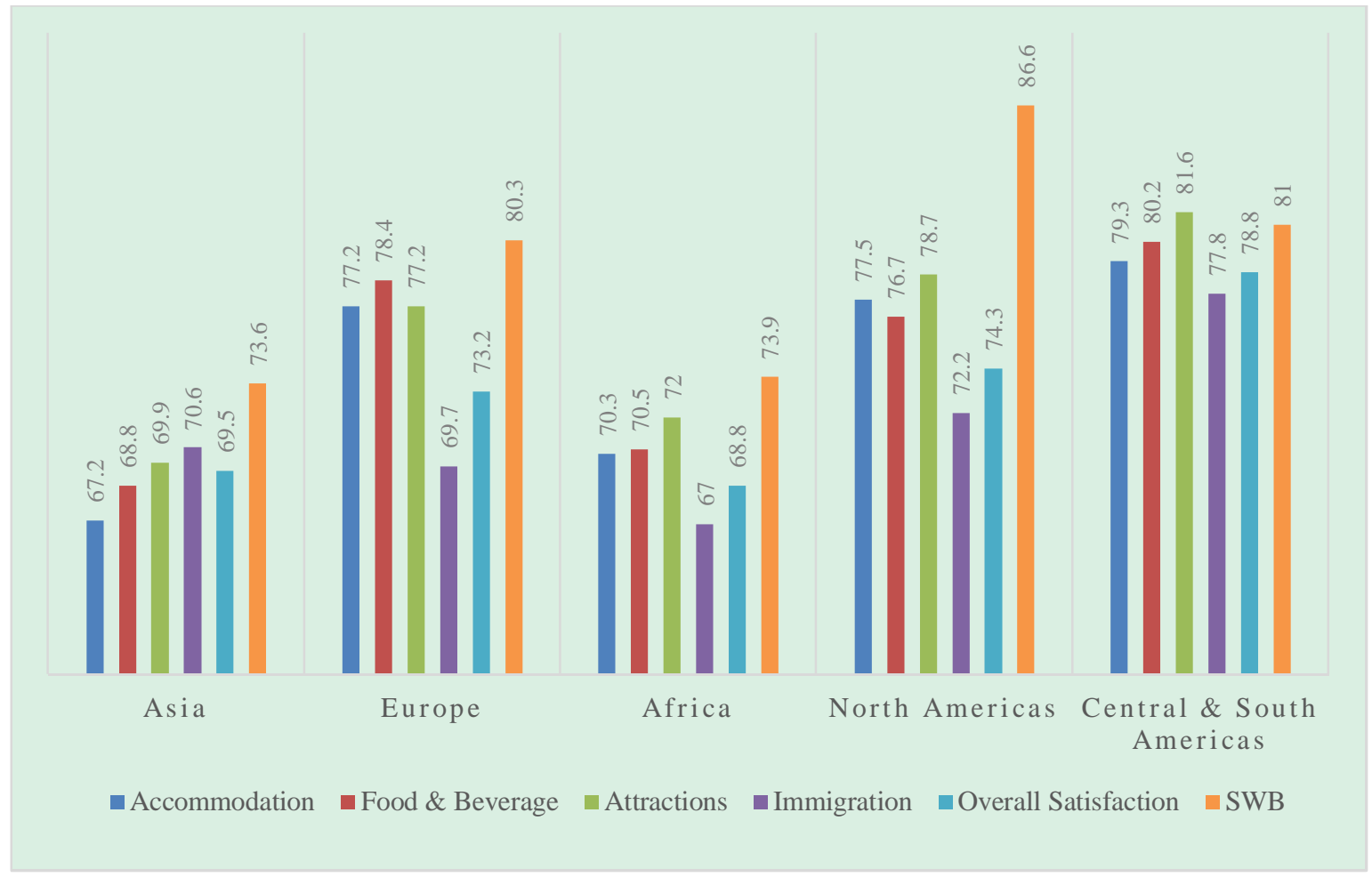

Figure 5 Calcuated TSIs and TWBIs of Key Source Regions

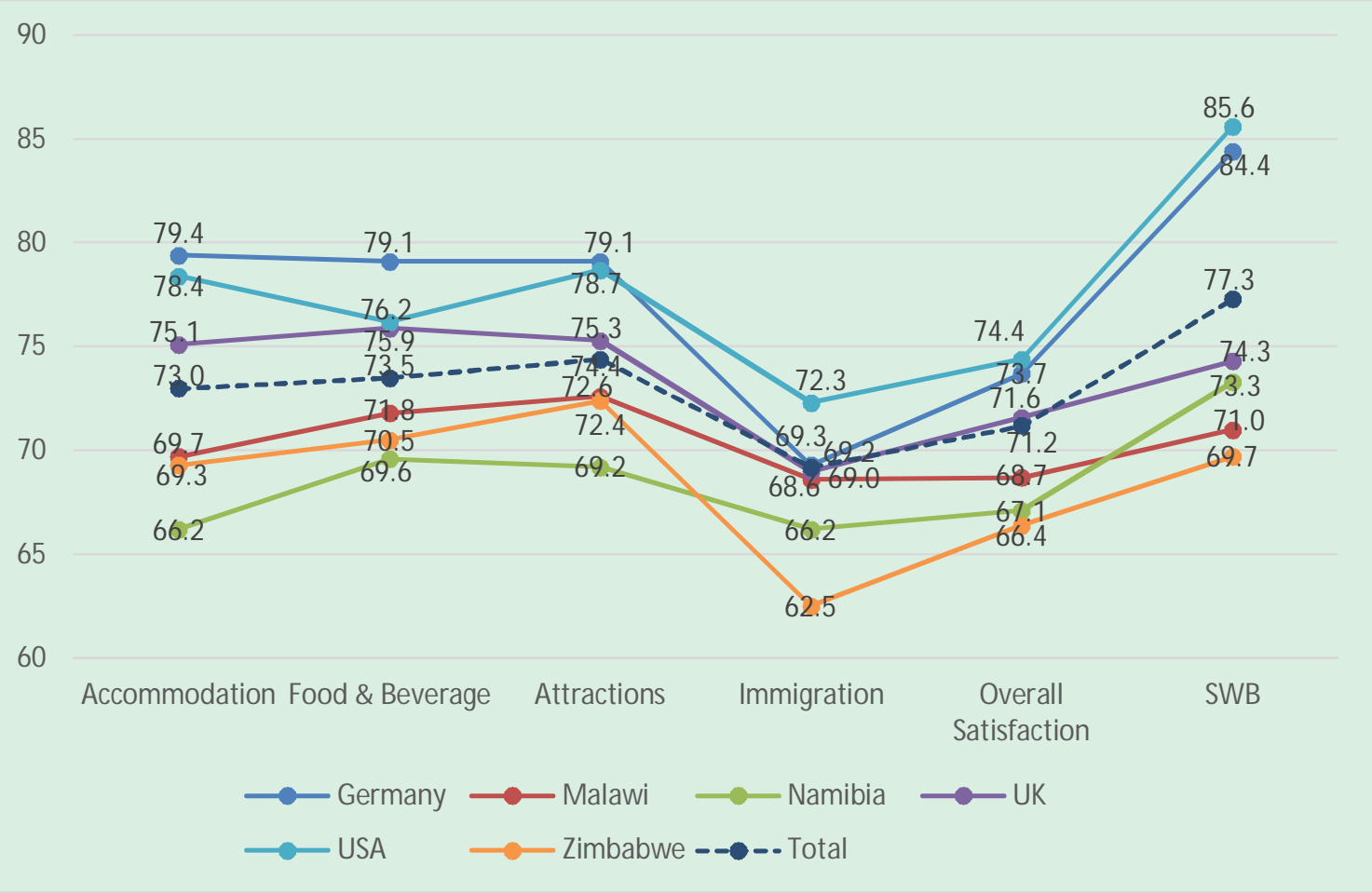

Figure 6 Calcuated TSIs and TWBIs of Key Source Markets 
Such differences were further confirmed by the results of six selected long-haul and short-haul source countries. Overall, Figure 6 suggests that the three long-haul markets, namely Germany, the USA and the UK, presented higher TSI and TWBI scores than the sample average, while the three African markets (Malawi, Namibia and Zimbabwe) had below average indices.

Useful conclusions for tourism service providers and destination managers could be drawn from the above understanding of the differences in tourists' evaluation of their experience and the further impact on their well-being that were identified between different segments and markets. This consistent and comparable index system provided a scientific foundation for benchmarking, and therefore pointed out strategic priorities and key directions for further improvements.

\section{CONCLUSION}

The purpose of this research was to examine the effect of tourists' satisfaction on their sense of SWB based on an index approach. The main contribution was the development of a new, innovative index system capturing tourist satisfaction and its causes and outcomes, particularly its impact on tourists' subjective well-being. Based on well-developed consumer satisfaction indices and a relatively new tourist satisfaction index system, the proposed new index system has rigorous theoretical foundations and presents further innovations from both theoretical and methodological perspectives. It extends the research on the impact of tourist experience on quality of life/subjective well-being. The universally applicable index system developed in this study is not only an analytical framework, but also an effective tool for destination management as well as managing individual businesses.

Through an empirical case of inbound tourism in South Africa, this study demonstrates how various indices are calculated and applied to different market segments for useful comparisons. The universal index system is particularly useful for benchmarking and drawing important conclusions on strategic management and marketing. It should be noted that the index system can also be used for longitudinal analysis to track the dynamics of tourist experiences, which can provide evidence on the effectiveness of certain management strategies.

Future studies should consider testing the proposed index system in other empirical settings, such as different destinations, different types of products (such as cruising and adventure tourism) or different market segments (such as senior and youth tourists). Another possible extension of the study is to examine the impact of tourists' satisfaction on the reduction of their work-related stress or vice versa, as some tourists tend to bring their work with them when they go on holiday, which may affect their level of satisfaction, hence their perception of QOL and SWB.

\section{ACKNOWLEDGEMENTS}

This research was paid for by the researchers own research funds.

\section{REFERENCES}

Ap, J. (2000). Understanding the Asian respondent when conducting tourism research: Some challenges, pitfalls and tips. Paper presented at the 31st Annual Conference Proceedings, Travel and Tourism Research Association. Travel and Tourism Research Association, San Fernando Valley, CA, 11-14 June 2000.

Augustyn, M., \& Ho, S. K. (1998). Service quality and tourism. Journal of Travel Research 37(1), 7175. DOI: $10.1177 / 004728759803700110$ 
Becker, J. M., Klein, K., \& Wetzels, M. (2012). Hierarchical latent variable models in PLS-SEM: Guidelines for using reflective-formative type models. Long Range Planning 45(5), 359-394. DOI: $10.1016 /$ j.lrp.2012.10.001

Chan, L. K., Hui, Y. V., Lo, H. P., Tse, S. K., Tso, G. K., \& Wu, M. L. (2003). Consumer satisfaction index: New practice and findings. European Journal of Marketing 37(5/6), 872-909. DOI: 10.1108/03090560310465189

Chen, Y., Lehto, X. Y., \& Choi, S. (2009). Effect of experience on cognition, affect and satisfaction: The case of Japanese visitors to Macau. Journal of Hospitality Marketing \& Management, $18(2-$ 3), 273-293. DOI: 10.1080/19368620802594151

Cho, B-H. (1998). Assessing tourist satisfaction: An exploratory study of Korean youth tourists in Australia. Tourism Recreation Research 23(1), 47-54. DOI: 10.1080/02508281.1998.11014819

Choi, T. Y., \& Chu, R. (2001). Determinants of hotel guests' satisfaction and repeat patronage in the Hong Kong hotel industry. International Journal of Hospitality Management 20(3), 277-297. DOI: $10.1016 / \mathrm{S} 0278-4319(01) 00006-8$

Crotts, J. C., \& Erdmann, R. (2000). Does national culture influence consumers' evaluation of travel services? A test of Hofstede's model of cross-cultural differences. Managing Service Quality: An International Journal 10(6), 410-419. DOI: 10.1108/09604520010351167

Dagger, T. S., Sweeney, J. C., \& Johnson, L. W. (2007). A hierarchical model of health service quality scale development and investigation of an integrated model. Journal of Service Research 10(2), 123-142. DOI: 10.1177/1094670507309594

Del Bosque, I. R., \& San Martín, H. (2008). Tourist satisfaction: A cognitive-affective model. Annals of Tourism Research 35(2), 551-573. DOI: 10.1016/j.annals.2008.02.006

Fornell, C. (1992). A national customer satisfaction barometer: The Swedish experience", Journal of Marketing 56(1), 6-21. DOI: 10.2307/1252129

Fornell, C., \& Larcker, D. F. (1981). Evaluating structural equation models with unobservable variables and measurement error. Journal of Marketing Research 18(1), 39-50. DOI: 10.2307/3151312

Fornell, C. G., Johnson, M. D., Anderson, E. W., Cha, J., \& Bryant, B. E. (1996). The American customer satisfaction index: Nature, purpose, and findings. Journal of Marketing 60(4), 7-18. DOI: $10.2307 / 1251898$

Fuchs, M., \& Weiermair, K. (2004). Destination benchmarking: An indicator-system's potential for exploring guest satisfaction. Journal of Travel Research 42(3), 212-225. DOI: $10.1177 / 0047287503258827$

Gilbert, D., \& Abdullah, J. (2004). Holiday taking and the sense of well-being. Annals of Tourism Research 31(1), 103-121.

Gold, A. H., Malhotram A., \& Segars, A. H. (2001). Knowledge management: An organizational capabilities perspective. Journal of Management Information Systems 18(1), 185-214. DOI: 10.1080/07421222.2001.11045669

Goodhue, D., Lewis, W., \& Thompson, R. (2006). PLS, small sample size, and statistical power in MIS research. Paper presented at the 39th Annual Hawaii International Conference on System Sciences (HICSS'06), IEEE Computer Society, Washington, DC, 4-7 January 2006.

Grönroos, C. (1984). A service quality model and its marketing implications. European Journal of Marketing 18(4), 36-44. DOI: 10.1108/EUM0000000004784

Hair, J. F., Hult, G. T. M., Ringle, C., \& Sarstedt, M. (2016). A primer on partial least squares structural equation modeling (PLS-SEM). Thousand Oaks: Sage Publications.

Hennig-Thurau, T., \& Klee, A. (1997). The impact of customer satisfaction and relationship quality on customer retention: A critical reassessment and model development. Psychology and Marketing 14(8), 737-764. DOI: 10.1002/(SICI)1520-6793(199712)14:8<737::AID-MAR2>3.0.CO;2-F

Hofstede, G., Hofstede, G. J., \& Minkov, M. (1991). Cultures and organizations: Software of the mind (vol. 2). London: McGraw-Hill.

Kim, H., Woo, E., \& Uysal, M. (2015). Tourism experience and quality of life among elderly tourists. Tourism Management 46(1), 465-476. DOI: 10.1016/j.tourman.2014.08.002 
Li, G., Song, H., Chen, J. C., \& Wu, D. C. (2012). Comparing mainland Chinese tourists' satisfaction with Hong Kong and the UK using tourist satisfaction index. Journal of China Tourism Research 8(4), 371-392. DOI: 10.1080/19388160.2012.729402

McDowall, S. (2010). International tourist satisfaction and destination loyalty: Bangkok, Thailand. Asian Pacific Journal of Tourism Research 15(1), 21-42. DOI:

Neal, J, Sirgy, M. J., \& Uysal, M. (1999). The role of satisfaction with leisure travel/tourism services and experience in satisfaction with leisure life and overall life. Journal of Business Research 44(3), 153-163. DOI: 10.1080/10941660903510040

Neal, J., Uysal, M., \& Sirgy, M. J. (2007). The effect of tourism services on travelers' quality of life. Journal of Travel Research 46(2), 154-163. DOI: 10.1177/0047287507303977

Oliver, R. (1980). A cognitive model of the antecedents and consequences of satisfaction decisions. Journal of Marketing Research 17(4), 460-469. DOI: 10.2307/3150499

Oliver, R. (1997) Satisfaction: A behavioral perspective on the consumer. Boston: McGraw-Hill.

Parasuraman, A., Zeithaml, V. A., \& Berry, L. L. (1985). A conceptual model of service quality and its implications for future research. Journal of Marketing 49(4), 41-50. DOI: 10.2307/1251430

Pizam, A., Neumann, Y., \& Reichel, A. (1978). Dimensions of tourist satisfaction with a destination area. Annals of Tourism Research 5(3), 314-322. DOI: 10.1016/0160-7383(78)90115-9

Rust, R. T., Zahorik, A. J., \& Keiningham, T. L. (1995). Return on Quality (ROQ): Making service quality financially accountable. Journal of Marketing 59(2), 58-70. DOI: 10.2307/1252073

Saayman, M. (2013). En route with tourism: An introductory Text. Potchefstroom, South Africa: Juta.

Saayman, M., \& Saayman, A. (2012). Shopping tourism or tourist shopping: Case study of South Africa's African tourism market. Tourism Economic 18(6), 1313-1329. DOI: 10.5367/te.2012.0169

Saayman, M., Marias, M., \& Krugell, W. F. (2010). Measuring success of a Wine Festival - is it really that simple? South African Journal for Research in Sport, Physical Education and Recreation 32(2), 95-107. DOI: 10.4314/sajrs.v32i2.59299

Saayman, M., Martin, J. C., \& Roman, C. (2015). There is no fuzziness when it comes to measuring quality of service. Paper presented at the IATE conference. Hong Kong Polytechnic University, Hong Kong, 30 June-3 July 2015.

Sirgy, M. J. (2010). Toward a quality-of-life theory of leisure travel satisfaction. Journal of Travel Research 49(2), 246-260. DOI: 10.1177/0047287509337416

Sirgy, M. J., \& Lee, D. J. (2006). Macro measures of consumer well-being (CWB): A critical analysis and research agenda. Journal of Macromarketing 26(1), 27-44. DOI: $10.1177 / 0276146705285669$

Sirgy, M. J., Rahtz, D., \& Samli, A. C. (2003). Advances in quality-of-life theory and research. New York, NY: Springer-Science and Business Media.

Sirgy, M. J., Grzeskowiak, S., \& Rahtz, D. (2007). Quality of college life (QCL) of students: Developing and validating a measure. Social Indicators Research 80(2), 343-360. DOI: 10.1007/s11205-005-5921-9

Sirgy, M. J., Kruger, P. S., Lee, D. J., \& Grace, B. Y. (2011). How does a travel trip affect tourists' life satisfaction? Journal of Travel Research 50(3), 261-275. DOI: 10.1177/0047287510362784

Song, H., Li, G., Van der Veen, R., \& Chen, J. L. (2010). Assessing mainland Chinese tourists' satisfaction with Hong Kong using the tourist satisfaction index. International Journal of Tourism Research 13(1), 82-96. DOI: 10.1002/jtr.801

Song, H., Van der Veen, R., Li, G., \& Chen, J. L. (2012). The Hong Kong tourist satisfaction index. Annals of Tourism Research 39(1), 459-479. DOI: 10.1016/j.annals.2011.06.001

South African Tourism. (2015). 2015 Annual tourism report. South African tourism: Strategic Research Unit, South Africa. Retrieved from http://www.southafrica.net/uploads/files/2015_Annual_Report_v10_05082016.pdf(accessed 15 February 2016). 
Teo, T. S. H., Srivastava, S. C., \& Jiang, L. (2008). Trust and electronic government success: An empirical study. Journal of Management Information Systems 25(3), 99-132. DOI: 10.2753/MIS0742-1222250303

The Hong Kong Polytechnic University. (2015). The Hong Kong Polytechnic University Tourist Satisfaction Index and Tourism Service Quality Index 2015. Hong Kong: The Hong Kong Polytechnic University.

Tokarchuk, O., Maurer, O., \& Bosnjak, M. (2015). Tourism experience at destination and QOL enhancement: A case for comprehensive congruity model. Applied Research in Quality of Life 10(4), 599-613. DOI: 10.1007/s11482-014-9342-2

Truong, T., \& Foster, D. (2006). Using HOLSTAT to evaluate tourist satisfaction at destinations: The case of Australian holidaymakers in Vietnam. Tourism Management, 27(5), 842-855. DOI: 10.1016/j.tourman.2005.05.008

Uysal, M., Sirgy, M. J., Woo, E., \& Kim, H. (2016). Quality of Life (QOL) and well-being research in tourism. Tourism Management 53, 244-261. DOI: 10.1016/j.tourman.2015.07.013

Weaver, P. A., Weber, K., \& McCleary, K. W. (2007). Destination evaluation: The role of previous travel experience and trip characteristics. Journal of Travel Research 45(3), 333-344. DOI: $10.1177 / 0047287506292702$

Westbrook, R. A., \& Oliver, R. L. (1991). The dimensionality of consumption emotion patterns and consumer satisfaction. Journal of Consumer Research, 18(1), 84-91. DOI: 10.1086/209243

Wu, H-C., \& Ko, Y. J. (2013). Assessment of service quality in the hotel industry. Journal of Quality Assurance in Hospitality \& Tourism 14(3), 218-244. DOI: 10.1080/1528008X.2013.802557

Zeithaml, V. A. (1988). Consumer perceptions of price, quality, and value: A means-end model and synthesis of evidence. Journal of Marketing 52(3), 2-22. DOI: 10.2307/1251446 
